O eixo e a roda, Belo Horizonte, v.25, n.2, p. 127-149, 2016

\title{
Mito da interioridade e crise da subjetividade: sobre um conto inédito de Domício da Gama
}

\section{Myth of interiority and crisis of subjectivity: on an unpublished short story by Domício da Gama}

\author{
Franco Baptista Sandanello \\ Universidade Federal do Maranhão (UFMA), Bacabal / Brasil \\ fbsandanello@gmail.com
}

Resumo: Trata-se de uma análise do conto inédito "Nivelado", de Domício da Gama, cujas polarizações conceituais suscitadas pelo narrador autodiegético - animal $\mathrm{X}$ ideal, objetividade $\mathrm{X}$ subjetividade - são reinterpretadas a partir da relação corpo X espírito. Mobilizase, para tanto, a análise de Franz Brentano sobre a necessidade de um novo instrumental para o estudo dos fenômenos mentais e a discussão de Thomas Nagel acerca da importância da vivência individual para o esclarecimento da constituição do conhecimento objetivo a partir da subjetividade. Neste sentido, avalia-se a relação entre subjetividade e pessoa narrativa e, por fim, destaca-se a importância das experimentações conceituais de "Nivelado" como antevisão da crítica ao positivismo e ao intelectualismo de grande parte da literatura do século XX.

Palavras-chave: Domício da Gama; conto brasileiro; Franz Brentano; Thomas Nagel.

Abstract: The present article analyses the unpublished short story "Nivelado", by Domício da Gama, whose intrinsic polarizations aroused by the autodiegetic narrator - animal X ideal, objectivity X subjectivity - are reinterpreted regarding the problem body X soul. In order to do so, it dialogues with Franz Brentano's analysis of the need for new 
tools to study mental events; and with Thomas Nagel's discussion on the importance of individual experience for further clarification of the constitution of objective knowledge from subjectivity. Therefore, it evaluates the relationship between subjectivity and narrative person, and, finally, it stresses out the importance of the conceptual and formal experimentations in "Nivelado" as a preview of twentieth century's literary critique on positivism and intellectualism.

Keywords: Domício da Gama; Brazilian short story; Franz Brentano; Thomas Nagel.

Recebido em 23 de maio de 2016.

Aprovado em 17 de agosto de 2016.

\section{Introdução}

Publicado no periódico $A$ Semana (RJ) a 18 de fevereiro de 1888 e ainda inédito em volume, ${ }^{1}$ o conto "Nivelado", do escritor e diplomata Domício da Gama, trata do problema da consciência na relação corpo $\mathrm{X}$ espírito por meio da oposição recorrente entre o par animal $\mathrm{X}$ ideal. Há nesse texto um forte teor crítico à ciência positiva (sobretudo a Carl Vogt e Auguste Comte, textualmente mencionados) que transpõe imponderadamente ideais antropomórficos - como a utilidade e a moralidade - para o estudo dos animais. A causa do mal-estar do narrador (que fala em termos do sentimento de uma carga terrível diante de tais ideias ao refletir sobre a naturalidade da existência e a reprodução dos sapos, por oposição a seus próprios dramas) encontra-se no fato de que a discussão teórica objetivista da ciência não reconhece a vivência individual própria aos fenômenos subjetivos, considerando-os, pois, como fenômenos de segundo plano em relação aos fenômenos materiais.

\footnotetext{
${ }^{1}$ Os volumes Contos a meia tinta (1891) e Histórias curtas (1901), agrupados recentemente na coletânea Contos (2001), deixam de contemplar diversos contos do autor, espalhados por jornais e revistas do fim do século XIX. Todavia, a par de muitas crônicas, ensaios e mesmo de um capítulo de romance, seis contos inéditos foram recuperados e analisados por Sandanello (2016). São eles: "A mancha", "Nivelado", "Fibra morta", "Scherzo", "Moloch" e "Os olhos".
} 
Propomos, pois, discutir a ligação entre tal repúdio científico da subjetividade (refletida nas oposições corpo X espírito, animal X ideal) e o uso da pessoa narrativa em "Nivelado" com o objetivo de atestar a importância dos traços subjetivos para esta relação. Tomamos ainda, como base de nossa discussão, o exemplo presente no artigo de Thomas Nagel "Quel effet cela fait, d'être une chauve-souris?", que faz sobressair a divergência entre os dois tipos de concepção, subjetiva e objetiva, ao analisar os pontos de encontro da experiência sensorial do homem e dos animais.

Mesclaremos, assim, a análise do texto de Domício às discussões conceituais mencionadas (da percepção animal à humana, e à narração) de forma a enfatizar, paralelamente, a riqueza de sua obra, bem como a necessidade de seu resgate hoje. Afinal, a escassa fortuna crítica sobre o autor demonstra um estado de quase ineditismo de sua obra (BORGES, 1998), sobretudo no que toca à discussão de sua produção especificamente literária - fazendo de "Nivelado" um texto como que duplamente inédito. ${ }^{2}$

\section{O problema da consciência na relação corpo $X$ espírito, animal $\mathrm{X}$ ideal, em "Nivelado"}

A relação entre a consciência e o meio exterior, ainda que se estabeleça com mais autonomia a partir da obra de Descartes, sempre esteve presente na filosofia. No entanto, uma das questões mais profícuas do século XX sobre essa relação surgiu paralelamente à tradição filosófica a partir da adaptação do estudo da natureza psicológica à metodologia científica de modelo substancialista. Tal confronto metodológico, proveniente do tratamento da psicologia enquanto ciência, constitui a raiz de uma grande parte do desenvolvimento da filosofia contemporânea, sobretudo da fenomenologia. A emergência da psicologia, do ponto de vista da história das ciências, constitui um momento em que a mera polarização entre espírito e matéria deixa de ser causa suficiente para garantir acesso epistêmico à natureza. $\mathrm{O}$ fato mesmo de o espírito ter sido sempre visado a partir de sua contraposição com a natureza física gera a necessidade de estabelecer-se um caráter específico para a subjetividade.

\footnotetext{
${ }^{2}$ A este respeito, cf. o levantamento da fortuna crítica de Domício da Gama em Sandanello (2015) e a posterior análise de sua obra, dividida em duas fases distintas, em Sandanello (2016).
} 
Não apenas a busca pela determinação da natureza psíquica se desdobra numa denúncia a certa tendência da consciência à materialidade, como também as ciências já estabelecidas - talvez bastante influenciadas pela tarefa kantiana de estabelecer os limites da percepção humana - começam a interrogar-se sobre a natureza da intelecção e sobre a fidelidade de sua possível correspondência com a ordem empírica do mundo. Lógicos e filósofos, tanto das matemáticas quanto da semântica formal, como Frege (1971) e Russell (2007), buscam uma significação formal de suas respectivas ciências. Tal via de mão dupla, inaugurada pela institucionalização do psíquico enquanto objeto de ciência, tem como uma de suas origens o entusiasmo com que Franz Brentano procura inverter a hierarquia das ciências ao buscar um tratamento da natureza psicológica em sua positividade na obra Psychologie du point de vue empirique. Segundo ele,

Não apenas a percepção interior é a única de uma evidência imediata; ela é verdadeiramente a única percepção no sentido próprio da palavra. Assim como nós a vimos, os fenômenos da percepção dita exterior não podem de forma alguma, mesmo por meios indiretos, serem demonstrados como verdadeiros e reais. E aquele que, de boa fé, tomaos pelo que parecem ser, será convencido do erro pela conexão dos fenômenos. A percepção dita exterior não é, rigorosamente, uma percepção; e assim podemos dizer que os fenômenos psíquicos são os únicos sobre os quais podemos falar de percepção no sentido próprio da palavra (BRENTANO, 1944, p. 105, tradução e grifo nossos). ${ }^{3}$

Ciente dos limites interiores da percepção, bem como alheado do mundo exterior pela realidade impositiva dos fenômenos psíquicos, o narrador autodiegético (GENETTE, 1972) de "Nivelado" dá a conhecer

\footnotetext{
3 "Non seulement la perception intérieure est la seule qui soit d'une évidence immédiate; elle est vraiment la seule perception au sens propre du mot. Ainsi que nous l'avons vu, les phénomènes de la perception dite extérieure ne peuvent aucunement, même par des procédés indirects, être démontrés comme vrais et réels. Et celui qui, de bonne foi, les a pris pour ce qu'ils paraissaient être, sera convaincu d'erreur par la connexion des phénomènes. La perception dite extérieure n'est pas, au sens rigoureux du mot, une perception; et ainsi nous pouvons dire que les phénomènes psychiques sont les seuls à propos desquels on puisse parler de perception au sens propre du mot."
} 
seu drama pessoal em um longo e ininterrupto parágrafo. As palavras que pronuncia, tal qual as gotas de chuva que caem sobre si, seguemse umas às outras em um ritmo desenfreado, atribuindo inicialmente à embriaguez a falta de conexão entre os fenômenos percebidos:

Chovia eterna, desoladamente. Há quantas horas, há quantos dias, há quantos séculos não o podia dizer eu, que sentia-me dissolver, embebido das lágrimas da tristeza imensa da Nuvem. Tristeza da Inimiga - fingida, só para apagar-me o fogo santo da alegria que acendera em mim a chama luminosa, a quentura revigorante do bom vinho. Eu tinha bebido muito. Tiveram inveja da minha felicidade. $\mathrm{E}$ meteram-me num cárcere de sombra e melancolia. $\mathrm{E}$ há séculos a chuva cai para vencer este arder indômito de viver, que sinto. Porque eu ia no passo da conquista, firme e arrogante, com o peito dilatado, respirando livre os aromas idílicos e nos olhos resplendores celestes, encheram-me a estrada de poças lamacentas, desfolharam-me as flores à rija ventania, rolaram, encharcaram na enxurrada as folhas secas, o meu tapete do sonho, cobriram de véus negros, cegantes, os olhos luminosos da minha doce amiga a Noite (GAMA, 1888, p. 4).

A relação que mantém com o mundo ao seu redor, praticamente desconhecido para si, vai além de uma relação causal, espacial, dinâmica, atingindo os limites da intencionalidade. Mais especificamente, o que caracteriza sua abordagem tateante, fragmentária e desconexa do passado e

[...] o que caracteriza todo fenômeno psíquico é aquilo que os Escolásticos da Idade Média chamaram a presença intencional (ou ainda mental) e o que nós podemos chamar - usando expressões que não excluem todo equívoco verbal - relação a um conteúdo, direção a um objeto (não necessariamente uma realidade) ou objetividade imanente. [...] Nós podemos então definir os fenômenos psíquicos dizendo que são os fenômenos que contém intencionalmente um objeto (BRENTANO, 1944, p. 102, tradução e grifo nossos). ${ }^{4}$

4 “[...] ce qui caractérise tout phénomène psychique, c'est ce que les Scolastiques du moyen âge ont appelé la présence intentionnelle (ou encore mentale) et ce que 
A duplicação do objeto percebido - a chuva torrencial que parece dissolver o narrador - é dada, para retomarmos a referência escolástica (intentio) de Brentano (1944), em termos de coisa real (esse reale) e de coisa "enquanto conhecida" (esse intentionale). A consciência singular tem sua própria percepção do objeto: perceber é ter imagens mentais, de forma que toda consciência é consciência de algo (não existindo em estado puro). Se quisermos compreendê-la em sua especificidade - e assim decifrar o sentido da inveja alheia, que faz da vida do narrador um cárcere - temos de não nos contentar com sua tematização (embriaguez) e admitir uma modalidade de existência exclusivamente relacional, que tem na transcendência em favor de um objeto seu modo de funcionamento primordial. $^{5}$

Assim, todos os fenômenos exteriores tornam-se subordinados aos fenômenos psíquicos, uma vez que seu acesso é dado por intermédio da percepção. Ou menos: pelo relato da percepção do narrador.

Por um lado, a alegria e o desejo que confessa existem na medida em que são relatados. Fenômenos como a cor, o som, o calor, só aparecem à sua consciência por intermédio da vivência psicológica. Tais considerações implicam, paralelamente, a vocação epistemológica da psicologia: dentre todas as asserções provenientes das ciências

nous pourrions appeler nous-même - en usant d'expressions qui n'excluent pas toute équivoque verbale - rapport à un contenu, direction vers un objet (sans qu'il faille entendre par là une realité) ou objectivité immanente. [...] Nous pouvons donc définir les phénomenes psychiques en disant que ce sont le phénomènes qui contiennent intentionnellement un objet (gegenstand) en eux."

${ }^{5}$ Neste sentido, não podemos dizer que o espírito é de natureza material. Contudo, Henri Bergson (2013, p. VII-VIII) mostra que o simples fato de nomeá-lo basta para pressupor certa materialidade. Comenta Vanessa Temporal (2011, p. 87) acerca da impropriedade espacial da linguagem como elo entre as duas primeiras obras de Bergson: "[...] a redação da segunda obra de Bergson, Matéria e memória, surge depois de apontado [no Ensaio sobre os dados imediatos da consciência] - ainda que de forma subordinada à questão da solidariedade do eu com a mudança - o caráter espacial da linguagem e sua incompatibilidade com a natureza temporal da interioridade. Será a partir desta discussão presente em sua primeira obra quanto à impropriedade da linguagem para exprimir a totalidade do real que podemos compreender o ponto de vista adotado pelo filósofo em sua segunda obra. Em outras palavras, podemos dizer que o ponto de vista do ato e do vivido é um resultado de uma questão desenvolvida já no Ensaio." 
consolidadas, como as matemáticas, a física etc., nenhuma pode pretender um estatuto de realidade sem assegurar a relação direta dos estados psicológicos com uma existência concreta. Assim, como observa Brentano (1944), o que a consciência visa não é uma realidade; antes, trata-se de uma objetividade imanente à consciência que pressupõe uma inexistência intencional sempre a ser vencida. ${ }^{6}$

Por outro, é preciso relevar o alto grau de desconfiança do narrador, que fornece apenas flashes de um passado mais ou menos próximo do presente da enunciação. ${ }^{7}$ Neste sentido, de maneira estrategicamente infiel ao transcorrer cronológico dos fatos (que assume o segundo plano, face ao efervescer de uma verdade subjetiva cada vez mais premente), sob uma apresentação existencial-relacional, o narrador conta sua história aos borbotões, motivado pela chuva torrencial que cai há horas, dias ou séculos. O aprofundamento psicológico da experiência temporal e o afunilamento (antes espraiamento) das medidas cronológicas faz com que o leitor pondere a verossimilhança interna do texto, que o protege de uma equiparação temporal imediata:

Transferindo os eventos para o plano mental, pode-se dispensar a sequência cronológica ordinária e prosseguir mantendo a continuidade, pois estes são válidos apenas por padrões externos, e não possuem nenhuma justificativa (exceto a conveniência do leitor) na evocação de processos mentais em que a memória associativa segue leis de

\footnotetext{
${ }^{6}$ Trata-se do que se convencionou chamar de o "problema de Brentano", ou o problema da intencionalidade. Há nessa tese uma abertura intencional da consciência para o mundo, mas sem que seu resultado tenha necessariamente um estatuto de realidade. Ela se estabelece havendo ou não a existência concreta do objeto tematizado. Trata-se, portanto, de uma teoria mentalista, segundo a qual não há contato com o mundo externo à consciência sem passagem pelas representações interiores.

${ }^{7} \mathrm{Na}$ clássica definição de Wayne Booth (1968, p. 158): "For lack of better terms, I have called a narrator reliable when he speaks for or acts in accordance with the norms of the work (which is to say the implied author's norms), unreliable when he does not". Os termos reliable e unreliable são de difícil tradução, e uma interpretação alternativa pode ser encontrada em Alfredo Carvalho (2005, p. 27, grifos do autor): “[...] ocorreu-me propor a tradução narrador infiel [...]. Essa denominação parece-me bastante prática, e não só bem-soante como imensamente sugestiva. Ademais, permite o uso de um substantivo correspondente: podemos falar na infidelidade narrativa".
} 
sequência puramente privadas e individuais (MENDILOW, 1972, p. 83$){ }^{8}$

Paralelamente, a dissolução perene do narrador em chuva, em vinho e em lágrimas preenche com um conteúdo trágico o recipiente da "sequência cronológica ordinária" (MENDILOW, 1972, p. 83) contra a qual se embate. A repetição de maiúsculas alegorizantes ("Nuvem", "Inimiga", "Noite") opera a interpretação unívoca da tristeza pela razão, que se não deixa analisar. Uma série de dúvidas surge à medida que as orações se acumulam, e não é sem estranheza que nos deparamos com a menção do narrador à "inveja alheia", supostamente responsável por lançá-lo "num cárcere de sombra e melancolia", em contraste com o "passo da conquista, firme e arrogante", proporcionado pela bebida (GAMA, 1888, p. 4). As perguntas são, assim, inevitáveis: conquista de quê? Quem lhe inveja? Tal cárcere existe fora de seu devaneio?

A rigor, nenhuma dessas questões pode ser colocada per se: o drama do eu não se deixa avaliar pelo mesmo léxico empregado aos objetos materiais. A dependência que a consciência tem em relação ao mundo é apresentada sem que por este último se entenda automaticamente "materialidade". Colocar a relação do espírito com o mundo em termos de intencionalidade faz-nos necessariamente mudar de categorias. Ela exige um léxico intencional. No entanto, embora compreendamos o eu como não sendo uma coisa, somos obrigados a falar da subjetividade a partir de um léxico substancialista. Somos obrigados a lidar com a natureza do espírito fazendo uso das categorias que usamos para os objetos materiais. Henri Bergson (2013, p. 126) observa que, ao fazermos uso da linguagem, determinamos a natureza do objeto, e mesmo o que não ocupa lugar no espaço é tratado como possuindo uma natureza espacial. Portanto, eis a

\footnotetext{
${ }^{8}$ Tal procedimento de inversão do tempo conceitual no tempo psicológico remete ao que Mendilow (1972, p. 83) denomina de "troca-de-tempo" (diverso, porém não destacado, do "fluxo de consciência" que comenta na passagem referida): "A troca-de-tempo é ainda outra maneira de distribuir a matéria de exposição por todo o romance. Com efeito, faz da necessidade uma virtude pela fragmentação deliberada da sequência; todo o senso de continuidade é perdido, e as lacunas entre os incidentes tratados permanecem, portanto, sem serem notadas." Podemos pensar a respeito de "Nivelado" numa "troca-de-tempo" semelhante, em que o passado (distante, próximo) e o presente são intercalados, de forma a destacar, para além da construção linear do enredo, a perenidade do drama do narrador.
} 
dificuldade que a intencionalidade põe: como dizer os objetos psíquicos? Trata-se de um problema ontológico ou gramatical?

O léxico intencional é difícil e ameaça-nos com a ininteligibilidade, na medida em que escapa a uma abordagem materialista (linguagem oficial da ciência). É necessário encontrar um léxico autônomo que escape ao monismo fisicalista. De modo corrente, e como o narrador, falamos em termos intencionais ("eu sinto", "eu vejo uma árvore" etc.), mas há uma grande conotação de distância desses termos no que toca a um engajamento epistemológico. ${ }^{9}$

Não obstante, o trecho posterior parece indicar uma resposta:

E agora quem me visse vacilante e trôpego diria que eu estava bêbado. Triste é que eu estava. Vencia-me a mágoa, embebia-me a sombra, a morte quebrava-me as arrogâncias físicas. Havia uma força imensa superior oprimindo-me [...]. Sabia que era uma provação aquilo. Bem me tardava repousar, mas não na rua. Nem em casa. Uma modalidade física do Ideal insinuava-me que não era o melhor o que

\footnotetext{
${ }^{9}$ Gilbert Ryle (2005, p. 11-24) apresenta um estudo sobre este tema em que define o mito da interioridade como coisa mental e interior, baseando-se na denúncia de um falso realismo. É sempre sobre a matéria de que falamos. Não temos elementos para sairmos da categoria material. Bergson (2013, p. VII) mostra como apreender o espírito a partir das categorias moldadas para apreender a matéria resultou na emergência de problemas insolúveis, como o da liberdade, o da relação espírito X corpo e a apreensão da natureza da própria vida. Temos, portanto, como consequência, o fato de o realismo ganhar, após Brentano, uma conotação de teoria ingênua e perder força enquanto explicação da relação consciência $X$ mundo. Posteriormente, em linhas gerais, o problema corpo $\mathrm{X}$ sujeito irá articular-se em dois tipos de atitudes que fazem frente a essa teoria, e que levam em conta a mudança de categorias explicativas proveniente da noção de intencionalidade tal como concebida por Brentano (1944, p. 102): a do psicofisiologismo e a da redução fenomenológica. Com a primeira, temos um sistema de explicação que interpreta o comportamento a partir da constituição do organismo vivo, o que resulta na tendência de ignorar-se o caráter único da experiência subjetiva. Com a segunda, ainda que os conceitos e as ideias que nós empregamos quando apreendemos o mundo exterior sejam inicialmente aplicados a partir de um ponto de vista dependente de nosso aparelho perceptivo, nós os utilizamos para fazermos referência às coisas para além delas mesmas. Esta perspectiva fenomenal nos permite transitar entre pontos de vista e, ainda assim, pensar na coisa de maneira objetiva - mais objetiva que uma visão abstrata, na medida em que os fenômenos mentais só podem ser analisados levando-se em conta o caráter único da experiência subjetiva.
} 
eu pudesse desejar, porque seria cousa já sabida. Por isso eu não desejava cousa alguma. Caminhava duro, teso, com o enfatismo nos passos de saltimbanco em drama lírico, com investidas e arrancos trágicos, após longas pausas deliberativas, torvas de decisão explosiva (GAMA, 1888, p. 4).

Especificando o sentido de sua ebriedade, o narrador diz caminhar ao longo de uma rua sentindo uma força superior, que julga ser uma provação, atuar sobre si. Afirma gozar de uma dignidade íntima ao lutar contra tal força, como se uma certeza moral justificasse simultaneamente a embriaguez e a fraqueza das pernas, oprimidas por um destino injusto. E, em meio a frases desconexas, faz menção a uma "modalidade física do Ideal" que insinua "que não era o melhor o que [...] pudesse desejar, porque seria cousa já sabida. Por isso eu [...] desejava cousa alguma" (GAMA, 1888, p. 4), apontando uma possível chave de compreensão. Trata-se de um desejo honroso do ponto de vista individual, porém ilícito do ponto de vista coletivo (ou, ao menos, da opinião alheia, por ele reservada ao domínio da inveja).

Em meio à sondagem dos desejos íntimos do narrador, que parece retomar, a cada instante, seus lamentos de outrora, ${ }^{10}$ reaparece a chuva como moto contínuo da dissolução física. Seu corpo sofre com a iminência de uma mencionada "decisão explosiva", adiada após "longas pausas deliberativas" (ou índices de conservação de certa capacidade reflexiva, que insiste em dotar a agonia física de foros metafísicos). E a chuva ressurge sem alterações, inteira, una:

Depois como uma cortina recaindo cerrava-se-me a treva e eu escutava o cair da chuva, monótono, constante, inexorável. Há quantas horas, há quantos dias, há quantos séculos, toda a minha longuíssima existência tendo se escoado transida e enlameada sob o perpétuo rorejar dos prantos celestes e terrestres. A lembrança dos sóis, de

\footnotetext{
${ }^{10}$ Inteiramente avessas ao léxico intencional e da ordem puramente da consecução lógica dos eventos narrados: qual poderia ser o objeto de seu desejo, que faz do narrador, antiteticamente, um prisioneiro a caminhar livremente pelas ruas? Quem impede que ele se concretize, valendo-se de uma conveniência social infundada, capaz de prostrar um desejo não apenas legítimo, mas ideal ("Ideal”), apenas por não consegui-lo para si (i.e., quem o inveja)? etc.
} 
tão apagada, era mítica. Sempre assim vivi, na solidão sombria, nas lágrimas. O resto, alegrias e luz, são os poetas que sonham. Maus poetas! fazendo-me sofrer... (GAMA, 1888, p. 4).

O trecho parece apontar que a "decisão explosiva" de conquistar seu desejo à força (invalidando, pois, seu direito de possuí-lo, tão somente pelo gozo da posse) despe gradativamente o Ideal há pouco louvado, em prol de sua materialidade direta, imediata, carnal. Em meio à dissolução da terra pela chuva e do corpo pelo pranto, dissolve-se também a razão, a começar pela memória: o sofrimento presente oblitera a "lembrança dos sóis" e substitui os dias passados por noites escuras e úmidas. Tudo o mais, como afirma, são sugestões literárias, externas, tomadas de livros de ("maus") "poetas" e enxertadas sensibilidade adentro, como elementos estranhos à vida interior, regrada pela alegria simples da satisfação dos desejos imediatos.

Trata-se, pois, do reconhecimento gradativo de que todo hiato entre o corpo e o espírito (i.e., entre o animal e o "Ideal") é ilusório. Contudo, "é a consciência que faz com que o problema corpo-espírito seja verdadeiramente difícil de resolver" (NAGEL, 1983, p. 193, tradução nossa). ${ }^{11}$ Logo, tal revelação somente é entrevista longe dos meios usuais (lembremos que o narrador recusa-se a voltar para casa, assim como se recusará em breve a voltar a casas de parentes e pretendentes). De maneira inversa, cercado pela lama, repara na alegria terra a terra dos sapos, a coaxar "seus castíssimos amores" em um charco:

Como se toda ventura não fosse a dos sapos, que aqui perto, no alagadiço bem cheio, entoam a potente roncaria epitalâmica celebrando os seus castíssimos amores. A chuva sabe - fecundante chuva, a lhes nutrir o gérmen que será a prole futura ainda implícita nos longos rosários, que a amorosa fêmea vai desfilando - inédita chuva! E porque não sou sapo eu, que tenho as mãos tão lascivas, a boca mais lasciva, o corpo todo menos nobre que estes puros animais? (GAMA, 1888, p. 4).

11 "C'est la conscience qui fait que le problème corps-esprit est vraiment difficile à résoudre." 
A proliferação dos sapos imundície adentro parece-lhe a mais sublime e verdadeira das coisas, e a linha sequencial de ovos e girinos, enfileirados uns atrás dos outros, assemelha-se-lhe a um longo rosário prece e milagre simultâneos - que ressignifica a experiência metafísica sob o mistério-sem-mistério da reprodução. Desta forma, o narrador chega ao mínimo múltiplo comum da vida humana enquanto recurso último para seu dilema pessoal (que ainda não se deixa entrever): a vida animal. O hiato (abismo) existente entre corpo e espírito somente é reavaliado na qualidade de um falso problema, inexistente na natureza e criado pela razão, à maneira daqueles livros de maus poetas, capazes apenas de obscurecer a vida. Observemos, todavia, que a ausência de sol (figura associada, ao menos desde o Iluminismo, à clareza da Razão) é o que possibilita o acúmulo de água na poça, e, consequentemente, a formação do charco que reproduz a vida. Ou seja, a vida exclusiva do intelecto pressupõe a exclusão da vida em si, enquanto que seu apagamento pressupõe o inverso. É precisamente a diferença que há nessa substituição o que encanta subitamente o narrador, capaz de compreender - também imerso na lama - a chave mestra para seus desejos inviáveis (artificiais).

Há, pois, um "caráter subjetivo da experiência" comum a homens e sapos:

Pouco importa a maneira pela qual a forma pode variar, o fato de que um organismo possui uma experiência consciente mostra que isso provoca um certo efeito de ser esse organismo. Isso pode implicar outras coisas quanto à forma que toma tal experiência, e isso pode (ainda que eu duvide) ter implicações quanto ao comportamento do organismo. Mas fundamentalmente um organismo possui estados mentais conscientes se isso lhe proporciona certo efeito de ser esse organismo - certo efeito para o organismo (NAGEL, 1983, p. 195, tradução nossa, grifos do autor). ${ }^{12}$

12 "Mais peu importe la manière dont la forme peut varier, le fait même qu'un organisme possède une expérience consciente, montre que cela fait un certain effet d'être cet organisme. Cela peut impliquer d'autres choses quant à la forme que prend cette expérience, et cela peut même (bien que j'en doute) avoir des implications quant au comportement de l'organisme. Mais fondamentalement un organisme a des états mentaux conscients si cela lui fait un certain effet d'être cet organisme - un certain effet pour l'organisme." 
Em "Quel effet cela fait, d'être une chauve-souris?", Thomas Nagel toma como exemplo não a vivência dos sapos, mas a dos morcegos, para ilustrar a ligação entre subjetividade e ponto de vista. E, à maneira do narrador de "Nivelado", pretende "buscar saber se um método qualquer nos permite extrapolar a partir de nosso ponto de vista a vida interior dos morcegos" (NAGEL, 1983, p. 197, tradução nossa) ${ }^{13}$ com base em suas formas de percepção, ${ }^{14}$ observando que nossa própria experiência é a responsável por fornecer à nossa imaginação sua "matéria de base" (NAGEL, 1983, p. 198, tradução nossa). No entanto, pondera que, mesmo que nos imaginemos transformados em morcegos (ou sapos), nunca iremos possuir sua mesma constituição neurofisiológica, o que torna incompleta a experiência de extrapolação da consciência:

[...] nós cremos que essas experiências têm também em cada caso uma característica subjetiva específica, que ultrapassa nossas aptidões em concebê-las. E se houver vida consciente no universo, é provável que parte dela não possa ser descrita nos termos gerais relativos à experiência de que dispomos (NAGEL, 1983, p. 198-199, tradução nossa). ${ }^{15}$

Conceber uma experiência estrangeira à nossa consiste, justamente, em uma das características mais marcantes da percepção humana. Temos a capacidade de enxergar o mundo enquanto algo comum e podemos estendê-la mesmo a seres vivos com sistemas perceptivos

13 “[...] chercher à savoir si une méthode quelconque nous permet d'extrapoler à partir de notre propre cas à la vie intérieure de la chauve-souris [...]".

${ }^{14}$ A maioria dos morcegos percebe o mundo exterior principalmente por sonar ou ecovocalização, que consiste na detecção de objetos situados dentro de seu campo perceptivo, sutilmente modulando seus gritos em alta frequência. As informações adquiridas por meio de sua configuração cerebral, que estabelece uma correlação entre os impulsos vindos do exterior e os ecos subsequentes, permitem aos morcegos orientarem-se a partir de discriminações precisas quanto à distância, à forma, ao movimento e mesmo à textura dos objetos.

15 " [...] nous croyons que ces expériences ont aussi dans chaque cas un caractère subjectif spécifique, qui dépasse nos aptitudes à les concevoir. Et s'il y a de la vie consciente ailleurs dans l'univers, il est vraisemblable qu'une partie de celle-ci ne pourra être décrite dans les termes les plus généraux relatifs à notre expérience dont nous puissons disposer." 
assinaladamente distintos do nosso. Se, portanto, perguntarmo-nos qual o efeito provocado ao existir enquanto sapo ou morcego, isto nos conduz à admissão da existência de fatos que não podem ser analisados a partir do critério humano de verdade, na medida em que não podemos dispô-los em proposições exprimíveis por nossa linguagem. Conquanto incapazes de identificá-los e de compreendê-los, não podemos negar a realidade ou a significação lógica dos fatos que não podemos descrever.

Neste sentido, a sequência do conto é ainda mais sugestiva:

Entendo agora o conselho sibilino do Ideal - seguir o impulso que me leva ao charco, prostrar-me, assapar-me de encontro a essa lama mole, visguenta, convidativa, nivelarme, pobre orgulhoso impotente! O conselho era do Ideal ou da fadiga extrema. Duas ideias de Vogt e de Augusto Comte faziam-me uma carga terrível - a da localização da lascívia batráquia, nos dedos, e a da inutilidade lógica do macho, da sua imoralidade dada a realização do ideal da virgem-mãe. Então, se os ideais humanos me anulavam naquilo em que eu mais julgava valer, na minha qualidade de macho, antes sapo, que não tem ideal, ou só tem os da vida - comida à farta e fêmeas fecundas - com uma renunciação quase mística aos contatos amorosos. A minha humanidade começava a pesar-me demais (GAMA, 1888, p. 4).

O problema dos excessos da razão decorre para o narrador dos falsos problemas positivistas, que pretendem dotar de uma validade científica, objetiva e externalista aquilo que deve passar por um crivo intencionalmente humano, subjetivo e animal. As ideias de $\operatorname{Vogt}^{16} \mathrm{e}$

\footnotetext{
${ }^{16}$ Carl Vogt dedica uma seção de um dos capítulos de seu Leçons sur les animaux utiles et nuisibles, les bêtes calomniées et mal jugées às virtudes reprodutivas do crapaud accoucheur (Alytes obstetricans, ou sapo-parteiro). Adaptado a ambientes secos, esse sapo vale-se da umidade de poças e pequenos charcos para a reprodução de seus ovos, "gestados" pelo macho: "Se alguém desejasse negar ainda que os mal afamados sapos pudessem servir de exemplos de tenras virtudes, eu o lembraria do sapo dito parteiro (Alytes obstetricans). A fêmea põe um rosário de ovos circundados por uma pele espessa, que se enrijece a ponto de parecer uma massa de borracha. O macho ajuda-a a gestar essa massa de ovos, que ele enrola ao redor das pernas; depois ele vai, com seu fardo, esconder-se debaixo de muitos pés de profundidade na argila úmida, e lá fica semanas inteiras sem alimento, num buraco negro, para fazer eclodir os ovos" (VOGT, 1897, p. 99, tradução nossa de: "Si quelqu'un voulait nier encore que les
} 


\section{Comte ${ }^{17}$ constituem "uma carga terrível” para ele, que, contrário à leveza}

crapauds mal famés puissent fournir des exemples recommandables de tendres vertus, je lui rappellerais le crapaud dit accoucheur (Alytes obstetricans). La femelle pond un chapelet d'oeufs entourés d'une peau épaisse, qui se dourcit au point de ressembler à une masse de caoutchouc. Le mâle l'aide à mettre au jour cette masse d'oeufs qu'il enroule autour de ses jambes; puis il va, avec son fardeau, se cacher souvent à plusieurs pieds de profondeur dans de l'argile humide, et il reste là des semaines entières sans nourriture, dans un trou noir, pour y faire éclore les oeufs"). Trata-se, pois, de um sapo que não depende tanto do macho para sua reprodução quanto da umidade e da ausência de iluminação, que fazem eclodir os ovos postos pela fêmea e apenas "gestados" pelo "parceiro". A referência a Vogt é interessantíssima para a avaliação do narrador, pois evidencia aquilo mesmo que ele procura esconder: a impossibilidade de consumação sexual de seus desejos. Ademais, as palavras de Marieta, mencionadas a seguir, são como ovos depositados no fundo de sua consciência, e que vão ganhando corpo à medida que o narrador se deixa levar pela tristeza causada, em parte, pelos preconceitos da amada. Para mais informações a respeito do sapo-parteiro, cf. Bischoff (1843, p. 619-620).

${ }^{17}$ No que diz respeito a Auguste Comte, a menção ao chefe da escola positivista, imediatamente ao lado à de Carl Vogt, faz pensar naquela parte de Système de politique positive em que o filósofo defende a instrumentalização do desejo sexual por meio de um culto à mulher, enquanto estágio intermediário ao culto da Humanidade: "Somente o culto feminino, primeiro privado, depois público, pode preparar o homem para o culto real da Humanidade. [...] E não é apenas na existência coletiva que o positivismo fará sentir claramente o elo entre o presente e o conjunto do passado e mesmo do futuro. Ao ligar todos os indivíduos e todas as gerações, sua doutrina familiar permitirá a cada um reavivar suas mais caras recordações, num regime em que a vida privada se unirá profundamente à vida pública" (COMTE, 1851, p. 261, tradução nossa de: “C'est donc le culte féminin, d'abord privé, puis public, qui peut seul préparer l'homme au culte réel de l'Humanité. [...] Ce n'est pas seulement dans l'existance collective que le positivisme fera nettement sentir la liaison du présent avec l'ensemble du passé, et même de l'avenir. En liant tous les individus et toutes les générations, sa doctrine familière permettra à chacun de mieux raviver ses plus chers souvenirs, dans un régime où la vie privée se rattachera profondément à la vie publique"). É escusado apontar o quanto as passagens de Vogt (1897) (cf. nota 15) e Comte (1851) possuem de uma antropotécnica viciosa, que pretende ditar o comportamento individual a partir de supostos benefícios à ordem coletiva. Veja-se, ainda, a seguinte passagem, que parece repetir a lógica acessória do macho, discutida a respeito do sapo-parteiro em Vogt (1897): “Desde então nós concebemos que a civilização não apenas dispõe o homem a melhor apreciar a mulher, como também aumenta a participação desse sexo na reprodução humana, que deve, no limite, emanar unicamente dele" (COMTE, 1851, p. 277, tradução nossa de: "Dès lors on conçoit que la civilisation, non-seulement dispose l'homme à mieux apprécier 
dos sapos, sente-se pesado e desproporcional. A suposta inutilidade lógica dos machos na cadeia evolutiva, bem como a localização da sensualidade batráquia nos dedos, tornam-se ideias absurdas tão logo contrapostas à "lama mole, visguenta, convidativa", que, sem argumentos mirabolantes, resolve os questionamentos orgulhosos e impotentes da ciência positiva. Por conseguinte, dissociam-se as ideias (positivismo) do Ideal (animal). Para que a humanidade não se torne um fardo excessivo, é necessário despi-la das opressões científicas e aceitar os ideais da vida ("comida à farta e fêmeas fecundas"), renunciando aos desejos que a contradigam ("contatos amorosos").

De certa forma, tais questões parecem contradizer-se. Embora o narrador faça o elogio da vida animal como solução dos falsos problemas do intelecto, seu drama amoroso, que esconde certa insistência gozosa no sofrimento, evoca a impossibilidade de ficar com a mulher amada, sendo obrigado a optar por outra, ao que parece, endinheirada e fértil. A questão do objeto de desejo do narrador remete ao contato artificialmente amoroso com alguém que não lhe garante o sustento nem a posteridade. Tal dilema, embora obscuramente apresentado, esclarece em partes o móvel da inveja alheia como sendo a de outros pretendentes por uma união naturalmente óbvia, além de socialmente vantajosa. No entanto, as reservas do narrador e os móveis de sua escolha são problematizados apenas no trecho seguinte:

Encostado ao muro, sentindo farfalharem-me as pernas, duas brasas por olhos e uma convulsão no queixo, meditei, hesitei longamente antes de aventurar-me pela viela da Baixeza. Eu sentia que entrar ali era decisivo. Havia alguma coisa ou alguém que me puxava para trás, dobrando-me pelo peito, fatigando-me ainda mais. Mas só depois que pus-me em marcha compreendi que o obstáculo era a flagelante frase de Marieta naquela noite em que eu por bravata fazia o elogio da embriaguez - "O homem que eu visse um dia embriagado nunca me poderia entrar no coração" (GAMA, 1888, p. 4).

la femme, mais augmente la participation de ce sexe à la reproduction humaine, qui doit, à la limite, émaner uniquement de lui"). Assim, as referências a Comte e Vogt evidenciam o poder (avassalador) outorgado à ciência em fins do século XIX. Não sem motivo, o narrador sente-se ameaçado pelo não lugar de seus desejos, abandonado em meio ao lamaçal, sem lembranças claras do passado nem perspectivas de futuro. 
Recusando-se hesitantemente a pagar pelo sexo, inteiramente contrário ao "desejo explosivo" da realização amorosa (que constituiria moralmente uma "Baixeza", termo expresso por mais uma maiúscula alegorizante), o narrador sente-se prostrado pela frase de Marieta (a amada, enfim, cujo nome é dado a conhecer), que, por sua vez, rechaça a ebriedade como algo sumamente ultrajante. Tal repúdio é o que leva o narrador, ironicamente, a beber, como se descobrisse em sua amada uma falta igualmente indecorosa - a da estreiteza de pensamento. Parece contraditório que seja esse o motivo de sua tristeza tão profunda (poderia uma frase dita numa ocasião banal, au jour le jour, prostrá-lo de maneira tão profunda, como os sapos cuja sorte inveja, no charco?): "Na pacífica e honesta sala de jantar entre o cálice de Madeira ainda cheio e a xícara de café $[\ldots]$ era mais uma banalidade virtuosa que ela pronunciava com a sua voz preguiçosa, [...] graciosíssima, só dela, da boa e carinhosa amiga" (GAMA, 1888, p. 4). Sob um primeiro exame, e ainda sob a sugestão do moto contínuo da chuva, a reação do narrador soaria, em muitos sentidos, uma tempestade em copo d'água. No entanto, o valor de sua reação pessoal reside justamente na peculiaridade (in-tempestividade) pela qual ocorre. Afinal, é como se sente (por oposição ao discurso ba(na) lizador da ciência) o que motiva a narração: "Mas aqui, na noite escura, com os pés na lama fria, impelido ao charco pela força combinada dos silogismos e do álcool, aquela frase era a minha sentença antecipada" (GAMA, 1888, p. 4).

Apenas ao cair na lama, imergindo seu corpo todo (joelhos, coxas, barriga, mão, rosto, barba e boca) na massa vital em que coaxam os sapos, é que o narrador consegue entender o real alcance do repúdio de Marieta:

Pensei no olhar de repugnância e nojo de Marieta, se me visse de cara, barba e boca enlameadas, estirado na estrada como um bêbado, e chorei. Não digo como chorei, porque só o entenderia quem já chorou assim. Acalmou-me por fim o mesmo pranto e sorri dos jatos d'água lamacenta que as convulsões do peito, batendo arquejante, fazia saltar. Era brincadeira de porco ou de sapo. Familiarizava-me com a lama (GAMA, 1888, p. 4).

A dissolução final da memória pelas lágrimas escapa ao alcance interpretativo, e proporciona, finalmente, ao narrador a satisfação animal do contato com a lama. Pode-se dizer, inclusive, que ele começa a 
chafurdar na poça qual um porco ou um sapo, já inteiramente "nivelado" com o ambiente. Assim, conclui-se a evolução de seu drama romântico (impossibilidade da consecução amorosa) no completo apagamento da individualidade (possibilidade da consecução animal-existencial), por meio de "jatos d'água" indiscerníveis que remetem igualmente a convulsões de pranto e a brincadeiras com a lama.

Neste sentido, o desfecho do conto é sintomático, uma vez que a trama permanece sem resolução. Inversamente, surgem novos e importantes elementos no ultimo parágrafo, logo desconsiderados pela visão descomplicada do narrador-porco-sapo, a somar lembranças esparsas e desconexas:

Estendi-me comodamente e como a água me entrasse no sovaco lembrei-me da carta, que trazia no bolso, do tio Luiz, convidando-me para ir passar com ele uns dias na fazenda e do sorriso da prima Georgina, que era uma carícia... Depois entrei a estudar a melodia de dois pingos d'água que, ora alternos ora juntos, caíam de um galho d'árvore em uma poça perto da minha orelha esquerda e parecem-me que a Marche de pluie de Richepin ensaiavase ali para irradiar-se depois, crescente, desoladora. A cabeça rolou-me, desfalecida e, com a face na lama, espojado, adormeci sem cuidar por quantas horas, por quantos dias, por quantos séculos, acalentado pelo sussurro imenso da chuva (GAMA, 1888, p. 4).

Há pouco a dizer a respeito das duas personagens novas, tio Luiz e prima Georgina, evocadas inesperada e unicamente a partir do contato d'água com o sovaco. Entretanto, tal ausência de informações é demasiado significativa, tendo em vista a finalidade oculta do convite do tio na carta molhada. ${ }^{18}$ Da prima, retoma-se reticentemente a carícia do sorriso, sem que se conclua nada, tampouco. Inversamente, a atenção do narrador é colocada por completo no instante presente da percepção. É

\footnotetext{
${ }^{18} \mathrm{O}$ que traria a carta? Um possível casamento arranjado, avesso à paixão do narrador por Marieta, reduziria o conto a uma repetição anacrônica da tradição romântica, sob a chave temática do amor impossível etc. Seu silenciamento é, pois, uma crítica implícita à literatura folhetinesca, e uma demonstração consciente das expectativas de leitura motivadas pelo contexto original de publicação de "Nivelado".
} 
a partir das gotas de chuva que julga ouvir "a Marche de pluie de [Jean] Richepin", ${ }^{19}$ poema cujas aliterações - "Il tomb de l'eau, plic ploc plac, / Il tomb de l'eau plein mon sac" (RICHEPIN, 1881, p. 22) - são os últimos resquícios de literatura em sua consciência. Dissolve-se, com isso, seu drama intelectual simultaneamente à carta do tio, cuja escrita é desmanchada pela água da poça, levando consigo a única chave possível de decifração do enredo.

19 "Marche de pluie", de Jean Richepin, é um poema inserido na primeira parte de $L a$ chanson des gueux, intitulada "Gueux des champs: chansons des mendiants". De fato, mendigo é o próprio narrador, no sentido em que é despojado de todo artifício social e encontra, em meio à completa miséria do charco, um sentido superior, imaterial, de consciência. Segue-se o poema, na íntegra, para que se avalie a comparação entre suas aliterações e a melodia das gotas de chuva, conforme avaliadas pelo narrador: "Il tomb de l'eau, plic, ploc, plac, / Il tomb de l'eau plein mon sac. // Il pleut, ça mouille / Et pas du vin! Quel temps divin / Pour la guernouille // Il tomb de l'eau, plic ploc plac, / Il tomb de l'eau plein mon sac. // Cochon, patauge! / Mais le cochon / Trouve du son / Au fond de l'auge. // Il tomb de l'eau, plic ploc plac, / Il tomb de l'eau plein mon sac. // Le cochon bouffe; / Toi, vieux clampin, / C'est pas le pain, / Vrai, qui t'étouffe. // Il tomb de l'eau, plic ploc plac, / Il tomb de l'eau plein mon sac. // Bah! sur la route / Allons plus loin. / Cherche un bon coin / Truche une croûte. / Il tomb de l'eau, plic ploc plac, / Il tomb de l'eau plein mon sac. // Après la pluie / Viendra le vent. / En arrivant / Il vous essuie. // Il tomb de l'eau, plic ploc plac, / Il tomb de l'eau plein mon sac" (RICHEPIN, 1881, p. 22-23). Perceba-se a série de elementos aí presentes (o moto contínuo da chuva, as figuras da rã e do porco, o contraste da água com o vinho, o vagar dificultoso do andarilho pela estrada) que embasa um evidente diálogo intertextual entre o conto e o poema, digno de estudo em uma leitura comparativa à parte. Em todo caso, segue-se à "Marche de pluie" o poema "Ce qui dit la pluie" (imediatamente posterior, igualmente incluído em "Gueux des champs"), cuja mudança de tom é igualmente significativa. A respeito de ambos, comenta Howard Sutton (1961, p. 98, tradução nossa de: "Marche de pluie' elenca as misérias causadas pela chuva a um mendigo perambulando por uma estrada, enquanto 'Ce qui dit la pluie' o lembra de que a chuva faz o trigo germinar e de que, quando a colheita é boa, os fazendeiros são generosos". (“"Marche de pluie' enumerates the miseries brought by the rain to a tramp trudging along a country road, while 'Ce qui dit la pluie' reminds him that the rain causes the wheat to sprout and that when crops are good the farmers are open-handed.") Destaque-se a opção de Domício da Gama pelo primeiro dos dois poemas de Richepin dedicados à chuva, recusando a visão idílica de natureza e de comunidade social presente em "Ce qui dit la pluie". 
Logo, por meio da completa dissolução do intelecto e de sua expressão escrita, encerra-se o conto, com um implícito elogio do animal sobre o ideal, ou do corpo sobre o espírito, pressuposto pelo triunfo final e silencioso do sono sobre (sob) a lama.

\section{Conclusão}

O conto "Nivelado" dialoga, pois, com questões caras à ciência e à filosofia (sob os pares corpo X espírito, animal X ideal) e tece uma crítica bastante sensível ao positivismo, mediante as referências a Vogt e Comte. Ademais, ao optar por um narrador autodiegético que defende a imersão da consciência naquilo que há de existencialmente animal no homem, por oposição a toda forma de verbalização demasiado intelectualizada (retomemos a vitória da lama dos sapos sobre o desfecho concertado da carta misteriosa), antecipa na década de 1880 a crítica de grande parte da literatura do século XX às heranças do intelectualismo na construção do texto literário, questionando suas regras de construção pela dissolução do enredo. Tais motivos fazem de "Nivelado" um texto verdadeiramente precursor, reforçando a importância do resgate atual de Domício da Gama e de sua obra. 


\author{
FIGURA 1
}

Fac-símile de "Nivelado"

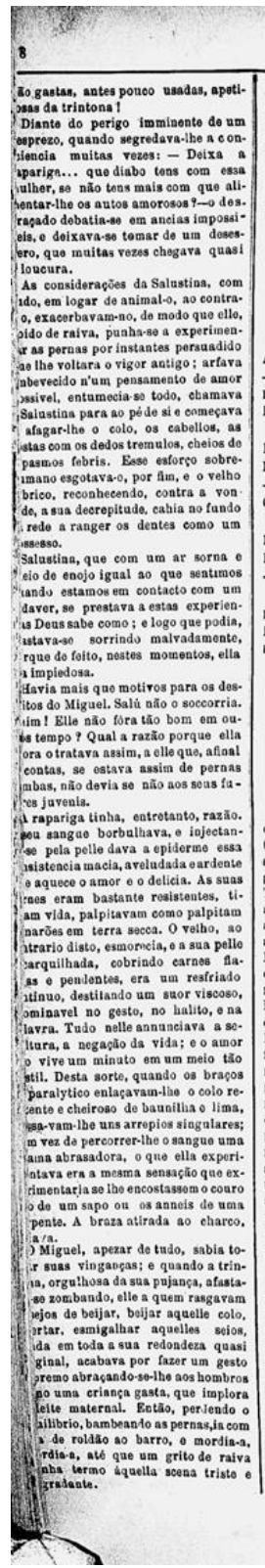

\title{
A SEMMANA
}

Com o roato humedecido pola baba,
Saluatina erguia-se, doixava o Miguel a catorear-se na crise de erotiamo, ef lançar-so no corrego como o musumano impuro.

YARARIPE JUNIOR. (Capitulo extrabido do um romance
inedito).

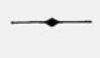

\section{RIMAS}

Andel em longas excarsōes diatantes : -Vi palacios, sacrarios, monumentos, Focos de industris, artisticos porteatos,
Praças soberbas, capiteis gigantes.

Em toda a parte ea lia nos semblantes Dures... luetas... identicos tornaentos... -Oade a patria do riso?!... Desaleatos Colhi apenas, mais erueis que d'antes

Parei, ematm.... E o coraçĩo da terra Pude encontrar : - So jubilos encerra -E'-lhe a ianocencia a unica rainba ! Rides? 1 Quimporta $t$ Ksse paiz de encanto $E$ 'de meu lar e pequenino canto, Em que alveja o tea berç, $\delta$ allia minha : AFForso CELSO JUXIOR

\section{NIVELADO}

Chovia eterna, desoladamente. A quantas horas, a quaatos diss, a quantos seculos não o podia dizer eu, que sentia-me dissolver, embebido das th. grimas da tristeza immensa da Navem. Tristeza da Inimiga - fingida, á para apagar-me o foge santo da alegria que aceendera ein mita a chamia luminosa, a quentura revigoranto do bom viato. Eu tinha bebido muito. Tiveram inveja da minha felicidade. E metteram-me n'um carcoro do sombra e melaneolia. E a seculos a chuva cahe para vencer este ardor indomito do viver, que sinto. Porque ea ia no passo da conquista, arme 8 arrogank, com o peito ditatado. respirando iling us a aos ollos resrada de pogas lanajos ram-me a mida do pogas lamacentas, desto rolaran, cila, rola con sonico, cobritain de veas negros, eègan agiga Noice, E agora quem me vioso acilianto e tropego diria gneen estava bebsdo. Triste 6 quo en estava. Vet cia-me a magoa, embobia-me a mom cia-me a magoa, embebis-me a sombra a morte quebrava-the as arrogancins physicas. Havia uma forç immensa superior opprimindo-me, procurandu desdo-me por traz dos joelhos para do bra-los e derrubar-me. Mas eu, que bem sei qual do om mim o sentido da major resistencis, intelirigava-me oen minhava hirto, inflexivel, ankilosado, como quem segue o destino. Sabia qqu era uma provaệlo aquillo. Bem me tardava repousar, mas nào as rua. Ne om casa. Uma modalidale physica do Idoal ianuava-mo quo não era o melthor cousa ja sabida. Por íso eu nĩ̃o deaso java cousa alguma. Camínhava duro, tezo, com o emphatismo nos passos de vestidas a es drama fricicos, após loagas pausas deliberativas, torvas de decisáo explosiva. E nesses impulsos aggressivos retomava-me a alegria horoiea, immotivada, de soldado no sssalto, abrindo-me uma porta á phanta. sia, que entre risos e descantes longin. quos, vagos, illuminava-me um recaato esouro do cerebro. Depois conso una cortina recahindo cerrava-se-me a treva ceu escatava o cakir da chava, nonotono, coustanto, inexoravet. A q̨uantas Loras, a quantos dias, a quantos seea. cristo mol, voda a cxisteacia todo se escondo transida prantos celosies orres prana dos abes, de tits apaga mythica, Sempre asuim vivi; sombria, nas lagrimas o resivalogrias e luz, sio os poetas que sopham, peetas: fazendo-me soffrer. Come se tedu ventura na o fosse a los sapos que agui perto, no alagasigo benos. que aqui porto, na alagasivo bem cheio, mica celebran 0 os seas eperitiala. amores. A chuva cahe - fecuudante chuva, a lhes nutrir o germen que serd a proto futura ainda implicita nos longos rosarios, que a amorosa fomea val desfando - vemdita ehuva! E porque nấo sou sapo eu, que teaho as máos táo laseivas, a bucen tanis lascira, - corpo todo menos nobro que estes paros aninaes? Eatendo agora o con. seltho sybillino do Ideal - soguir o Im. palso que me leva ao claareo, prostrarme, assapar-mede encontro a essa lama bolle, visguenta, convidativa, nivel:r. seltoera do Ldeal ou da fudiga extrema. Dass idéas de Vogte do Aaguato Comto Laziau-me uma carya lerrivel - a da loealisagáo da iasoivia bactracia, nos dedos a da inatilidade lugiea do maelao, da sua immoralicide dada a reali. sação do ldeal da virgom-nẫo. Entāo. so ob ideaes humanos me annullavam naquillo ern quo ou mais julgavas valer. na minha qualidade de macho, antes sapo, que não tem ideal, ou só tem os da vida-comida a tarla e feineas feedn. das-con uma renunciaçắo quasi mys. Lica a0s contactos amorosos. A minha humanidade comécara a pezar-me do mais. Uma viravolta pez-me en frento de uma vielia estreita, entre uma inaro razendo esquina e dma corea do ospinhos negrejaudo sobre atm clatino vago amarelloato,algau fampoa longe. Bacostado ao iadro, sentindo falharemme as perasas, dass brazas por olhos o uma convalsa to quenso, naedilol, hesitel longamente antes de aventurar-mo peia alli era da Baxiso. Bavia algao cor a deciso. dobra algue mo pachava para traz, ainda mais Mas só depois que puzano anda maso mas culoera a foellantephrazo do ca fazia o logio de qua por bravata mem ane on visese um dis ondriagalo mean que ca visse una dia embriagado

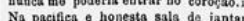
entre o ealix de Madeira ainda cheio a chicara de cafó que olla passaysormo. a clicara de cafó que olla passava-me, tîo leal, era mais uma banalidade virtuoss que ella pronunciara com a voz proguicesa, syllabando lentamente, com uma quasi affectaẹío de oxactils: e dogura, graciosissima, so della, da boa o carinhosa amign. Mas aqui, na noito esoura, com os pés na lama fria, impollido a chareo pola forca combi. nada dos ayllogitmos o do alcool, aquelia phraze era a minha sentenca anteolpada. Caminhando ou tiritava ao Irio do seu despreso o um solupo bo lhava-mo no peito o desfinzia-se eem es. talar e rotazia-se teimoso. De repente tropecei ; faltaratim-me as pernase eabil. com as mẫo para diante. Era foto. Senti frio primeiro nos joelthos o coxa encolthi a barriga a huinidate des. agradavel. Dopois retirel a mẫo direit. onterrada na lama e dosviei uu ramo que me arranlanva o rosto. Pensei no olhar de repugnaneis o nojo de Ma rietta, se me visso de cara, barba e cocen entsmeadas, estirado na estrad como uat bebado, 0 chorei. Níto digo qoras eliorei, porque so o entonderia puem Ji thorou assim. Acalnou-mo por tin o mesmo pranto e sorri dos ões do jeito, batiacenta quo as convul. Baltar. Bra briacadoirs de poreo, azin apo. apo. Familiarisava-me eom a lama. agua me entrasse no sorate da earta, que trazia no bolso, do Luiz, convidando-me pars is pasaer com elle uns dias na fazenda passar riso da prima Georgina, que ero sorearicis... Depois entrel a estudar molodia de doas pingos d'agnas que, or slternos ora juntos, cuhiam de um tho d'arvore em uma poça perto da minta oreltha esquerda e parecem.me que a Marche de pluie do Rieluepin ensaiavaso alli para irradiar-so depois, cres. cente, desoladora. A cabosa rolou-me desfallecida e, con a face na tama, pojado, adormeci som euidar por quan. tas horas, per quantos dias, por quan. los seculoz, acaleatado polo sussurro immenzo da eluva.

14 do Fevereiro 85 . DOHICIO DA GAMA

\section{AS RUGAS}

Vendo o sol de planetas já rodeado, Deus disse á natureza: $\rightarrow$ Filhs n'esso Turbilaâo de astros, matido que náo cesse Teu amor... Deixo a terra a teu cnidsdo... Disso, o com outros mundos occupado Fol-se. A filtha esto globo nĩo esquece Poe-libe agua a e, de agua acs rumes, viree Tudo... Tudo ella pints : os clos, o prado... E a Natareza tom mais gosto e geito Pondo em formosa tel o rosito da mulher - bello, perfeito.. Nas tudo canģ t.. e um dia - acaba-o ell Dando a torto a direito Profandas pince!adas a aquarella.

EDMUNDO DE BARROS.

\section{BELLAS ARTES}

Estonde-se ainds sobre estas colum naso prestigio d'aquelle que por tâ longo tempo e tâ.

Luiz Gomasga Duque Ratrada Gil desdo a fandaç̃o d's Semana, a toi, tade insbalavel que alimentou eata soc. 


\section{Referências}

BERGSON, Henri. Essai sur les données immédiates de la conscience. Paris: PUF, 2013.

BISCHOFF, Theodor Ludwig. Encyclopédie anatomique: traité du développement de l'homme et des mamifères, suivi d'une histoire du développement de l'oeuf du lapin. Tradução de Antoine J. L. Jourdan. Paris: J.-B. Baillière, 1843. t. VIII.

BOOTH, Wayne C. The rhetoric of fiction. Chicago: The University of Chicago Press, 1968.

BORGES, Luís Eduardo Ramos. Vida e obra do escritor Domício da Gama: um resgate necessário. 1998. 625 f. Tese (Doutorado em Letras) - Faculdade de Ciências e Letras, Universidade Estadual Paulista "Júlio de Mesquita Filho", Assis, 1998.

BRENTANO, Franz. Psychologie du point de vue empirique. Tradução de Maurice de Gandillac. Paris: Aubier; Éditions Montaigne, 1944.

CARVALHO, Alfredo Leme Coelho de. O narrador infiel. In: narrador infiel e outros estudos de teoria e crítica literária. São José do Rio Preto: Editora Rio-Pretense, 2005. p. 21-33.

COMTE, Auguste. Système de politique positive ou traité de sociologie. Paris: L. Mathias, 1851. v. I.

FREGE, Gottlob. Écrits logiques et philosophiques. Tradução de Claude Imbert. Paris: Seuil, 1971.

GAMA, Domício da. Contos à meia tinta. Paris: Lahure, 1891.

GAMA, Domício da. Contos. Rio de Janeiro: Academia Brasileira de Letras, 2001.

GAMA, Domício da. Histórias curtas. Rio de Janeiro: Francisco Alves, 1901.

GAMA, Domício da. Nivelado. A Semana, Rio de Janeiro, ano IV, v. IV, n. 161, p. 4, 18 fev. 1888. Disponível em: <http://memoria.bn.br/DocReader/ docreader.aspx $?$ bib $=383422 \&$ pasta $=$ ano $\% 20188 \&$ pesq $=$ nivelado $>$. Acesso em: 25 fev. 2016.

GENETTE, Gérard. Figures III. Paris: Seuil, 1972. 
MENDILOW, Adam Abraham. O tempo e o romance. Tradução de Flávio Wolf. Porto Alegre: Globo, 1972.

NAGEL, Thomas. Quel effet cela fait, d'être une chauve-souris? In: . Questions mortelles. Tradução de Pascal Engel e Claudine EngelTiercelin. Paris: PUF, 1983. p. 193-209.

RICHEPIN, Jean. La chanson des gueux. Paris: Maurice Dreyfus, 1881.

RUSSELL, Bertrand. Logic and knowledge: essays 1901-1950. London: Spokesman Books, 2007.

RYLE, Gilbert. Le mythe cartésien. In: Tradução de Suzanne Stern-Gillet. Paris: Payot, 2005. p. 11-24.

SANDANELLO, Franco Baptista. Sans désirs ni regrets: o impressionismo "a meia tinta" de Domício da Gama. In: LEÃO, Isabel Ponce de; MENDES, Maria do Carmo Mendes; LIRA, Sérgio (Org.). Artes e ciências em diálogo. Porto: Green Lines Instituto para o Desenvolvimento Sustentável, 2015. p. 1-10.

SANDANELLO, Franco Baptista. Sans désirs ni regrets: o impressionismo "a meia tinta" de Domício da Gama. 2016. 930 f. Pesquisa Pós-Doutoral (Pós-Doutorado em Estudos Literários) - Faculdade de Ciências e Letras, Universidade Estadual Paulista "Júlio de Mesquita Filho", Araraquara, 2016.

SUTTON, Howard. The life and work of Jean Richepin. Genève: Droz; Paris: Minard, 1961.

TEMPORAL, Vanessa de Oliveira. A contribuição de Matéria e memória para o estudo da linguagem na filosofia de Henri Bergson. Kinesis, Marília, v. 3, n. 6, p. 75-92, dez. 2011.

VOGT, Carl. Leçons sur les animaux utiles et nuisibles, les bêtes calomniées et mal jugées. Tradução de Gustave Bayvet. Paris: Schleicher Frères, 1897. 